\title{
PREPARATION AND CHARACTERIZATION OF (-)-EPIGALLOCATECHIN GALLATE LIPID BASED NANOPARTICLES FOR ENHANCING AVAILABILITY AND PHYSICAL PROPERTIES
}

\author{
Sabry A. Eltawela* ${ }^{1}$, Abdelaziz E. Abdelaziz ${ }^{2}$, Mahmoud A. Mahdi ${ }^{1}$, Hanaa A. \\ Elghamry ${ }^{1}$ \\ ${ }^{1}$ Department of pharmaceutics and industrial pharmacy, Zagzig university, Egypt \\ ${ }^{2}$ Pharmaceutical technology department, faculty of pharmacy, kafrelshiekh university, \\ Egypt
}

*Corresponding author: Email : $\underline{\text { seltawela71@gmail.com }}$

\begin{abstract}
:
(-)-Epigallocatechin gallate (EGCG) is the most abundant and biologically active polyphenol found in green tea. (-)-Epigallocatechin gallate (EGCG) is highly potent antioxidant therefore, it has great therapeutic effect against cancer disease. Furthermore, it has antibacterial and anti-inflammatory effect. but it has some limitations, such as the poor permeability, the highly affinity to intestinal P-glycoprotein efflux mechanism and short half-life. Therefore, it has very low oral bioavailability.

In current study, Precirol ${ }^{\circledR}$ ATO $5(\mathrm{P})$, glyceryl monostearate (GMS) and Compritol $^{\circledR} 888$ ATO (C) were selected as solid lipids and miglyol (M) and sesame oil (SO) as liquid lipids, to develop EGCG-NLC (nanostructured lipid carrier) and EGCGSLN (solid lipid nanoparticles). EGCG was successfully encapsulated into lipid nanoparticles to improve its bioavailability. EGCG-NLC and EGCG-SLN were formulated using a hot homogenization-ultrasonication technique, and the physicochemical properties were characterized. The developed EGCG-NLCs and EGCG-SLNs showed small and homogeneous particle size approximately (308 and 379 $\mathrm{nm}$ ) with entrapment efficiency around (76 and 49\%), respectively. Also, the resulted formulation EGCG-NLC3 appeared under transmission electron microscope in almost spherical shape.
\end{abstract}

Keywords: Epigallocatechin gallate, particle size, entrapment efficiency, transmission electron microscope and in-vitro release

\section{INTODUCTION}

(-)-Epigallocatechin gallate (EGCG) is the most abundant and biologically active polyphenol found in green tea. The total amount of catechins in one brewed cup of green tea consists of 50-80\% of EGCG, which makes approximately 200-300 mg (Klinski, 2013).

(-)-Epigallocatechin gallate (EGCG) has many biological functions such as antitumor, anti-aging, antibacterial and anti-inflammatory promising use as therapeutic agents due to their potent antioxidant activity and diverse biological properties (Granja 
et al., 2016).

Unfortunately, there are some limitations associated with EGCG, which negatively influences its functional benefits. These are, generally, the short half-life and the high sensitivity to light and heat (Grumezescu, 2016).

Furthermore, EGCG is unstable in alkaline and neutral medium (Kanwar et al., 2012) and, therefore, subjects to extensive degradation by gastrointestinal secretion. Furthermore, the poor permeability and the highly affinity to intestinal P-glycoprotein efflux mechanism. All of the introduced drawbacks leading to great low oral bioavailability of EGCG despite its high water solubility (Shtay et al., 2019). Hence, the previously studies reported to overcome these drawbacks and enhancing the oral bioavailability of EGCG through incorporation of EGCG in nanodelivery systems as liposomes (Zou et al., 2014).

In current study, to repair previously mentioned drawbacks and to enhance oral bioavailability, lipid-based drug delivery systems like nanostructured lipid carrier (NLCs) and solid lipid nanoparticle (SLNs) can be employed. Lipid nanoparticles systems (LNs) which have two generations. first, solid lipid nanoparticles (SLN) and second, nanostructured lipid carrier (NLCs) can improve the lymphatic transport of the hydrophilic drugs as EGCG and hence, increase its oral bioavailability (Mathur et al., 2019). LNs systems were recorded as an advanced drug carrier system than polymeric nanoparticle (Poonia et al., 2016).

Advantages of lipid nanoparticles delivery system over the advantages of polymeric nanoparticles because of the lipid component matrix and its properties, which is physiologically tolerated, resulted in avoidance of acute and chronic toxicity. In addition to, as good biocompatibility, protection for the incorporated compound against degradation and controlled release of drugs (Mendes et al., 2019).

Nanostructured lipid carriers (NLCs) composed of both solid and liquid lipids in certain proportion. Therefore, they offer various advantages over solid lipid nanoparticles (SLN) such as higher encapsulation efficiency, smaller size and low polymorphic changes (Rawal and Patel, 2019).

Generally, nanostructured lipid carriers (NLCs) are nano-drug delivery carrier, which own the advantages of polymeric nanoparticles, emulsion, and liposomes. Furthermore, (NLCs) are essentially composed of a biocompatible lipid core with entrapped lipophilic drugs and surfactant at the outer shell.

The aim of this study was to develop of NLCs and SLNs using Epigallocatechin gallate (EGCG) as a model drug. Furthermore, the physical characterization and quality issues of developed formulations were described and determined. Therefore, this study can offer the sequence steps for the development of NLCs and evaluation of their quality characteristics. 


\section{Materials and method}

Precirol ${ }^{\circledR}$ ATO 5 (P) and Compritol ${ }^{\circledR} 888$ ATO (C) were provided by Gattefossé (Nanterre, France). Glyceryl monostearate (GMS), Pluronic® F68 (polyoxy ethylene-polyoxypropylene polysorbate 60), miglyol-812, Epigallocatechin gallate (EGCG, 98\% purity), Methanol and Acetonitrile HPLC grade were purchased from Sigma Aldrich, Inc. (St. Louis, MI, USA). Sesame oil, Sodium hydroxide, potassium dihydrogen orthophosphate, Potassium Chloride, and Hydrochloric acid $(\mathrm{HCl})$ were supplied by El-Nasr Pharm. Chem. Company, Cairo (Egypt). Membrane filter (0.22 $\mu \mathrm{m})$ Millipore Iberica S.A.U.; Madrid (Spain).

All the above materials were in analytical grade and were used without further purification.

\section{Preparation of SLNs and NLCs}

EGCG nanostructured lipid carriers (EGCG-NLC) and EGCG solid lipid nanoparticles (EGCG-SLN) were prepared by hot homogenization - ultrasonication technique but with some few modifications. Briefly, a weighted amount of selected solid lipids for SLN and a weighted amount of selected solid-liquid binary lipids mixture for NLC $(5 \% \mathrm{w} / \mathrm{v})$ were melted at $5{ }^{\circ} \mathrm{C}$ above the melting point of solid lipid. A known concentration of EGCG (5\% w/v of lipids) was dissolved in the aqueous phase containing selected surfactant $(2.5 \% \mathrm{w} / \mathrm{v})$ then heated to the same temperature of lipid phase and added drop by drop to the lipid phase under magnetic stirring at $1500 \mathrm{rpm}$ for 5 min. After that, homogenization of the resultant pre-emulsion was performed at high speed of mixing about 20,000 rpm using an Ultra-Turrax T25 homogenizer (WiseMix ${ }^{\mathrm{TM}}$ HG15A, Daihan Scientific, Seoul, Korea) for 10 min (Anwar et al., 2020; Cortesi et al., 2017). The resultant $\mathrm{o} / \mathrm{w}$ nanoemulsions were subjected to probe sonication (ultrasonic processor, GE130, probe CV18, USA) at $60 \%$ amplitude for 10 min. The obtained NLC dispersion was left beside to reach room temperature. All formulations contents were illustrated in table 1 . 
Table (1): Suggested formulations of EGCG-NLCs and EGCG-SLNs

\begin{tabular}{|c|c|c|c|c|c|c|c|c|c|}
\hline \multirow[b]{2}{*}{ F. No. } & \multicolumn{3}{|c|}{ Solid lipids } & \multicolumn{2}{|c|}{ Liquid lipids } & \multicolumn{2}{|c|}{ Surfactants } & \multirow[b]{2}{*}{$\begin{array}{c}\text { wate } \\
\mathbf{r}\end{array}$} & \multirow{2}{*}{$\begin{array}{c}\text { ECC } \\
\text { G } \\
\text { mg }\end{array}$} \\
\hline & $\mathbf{P}$ & $\begin{array}{c}\text { GM } \\
\mathbf{S}\end{array}$ & $\mathbf{C}$ & $\begin{array}{c}\text { MYGLYO } \\
\text { L }\end{array}$ & $\begin{array}{c}\text { Sesam } \\
\text { e oil }\end{array}$ & $\begin{array}{l}\text { Twee } \\
\text { n } 60\end{array}$ & $\begin{array}{c}\text { Pluronic } \\
\text { ® } \\
\text { F68 }\end{array}$ & & \\
\hline NLC1 & 7 & & & 3 & & 3 & & 87 & 50 \\
\hline NLC2 & 7 & & & & 3 & 3 & & 87 & 50 \\
\hline NLC3 & 7 & & & 3 & & & 3 & 87 & 50 \\
\hline NLC4 & $\begin{array}{l}8 . \\
5\end{array}$ & & & 1.5 & & 3 & & 87 & 50 \\
\hline NLC5 & & & 7 & 3 & & 3 & & 87 & 50 \\
\hline NLC6 & & & 7 & & 3 & 3 & & 87 & 50 \\
\hline NLC7 & & & 7 & 3 & & & 3 & 87 & 50 \\
\hline NLC8 & & & $\begin{array}{l}8 . \\
5\end{array}$ & 1.5 & & 3 & & 87 & 50 \\
\hline NLC9 & & 7 & & 3 & & 3 & & 87 & 50 \\
\hline $\begin{array}{c}\text { NLC1 } \\
0\end{array}$ & & 7 & & & 3 & 3 & & 87 & 50 \\
\hline $\begin{array}{c}\text { NLC1 } \\
1\end{array}$ & & 7 & & 3 & & & 3 & 87 & 50 \\
\hline $\begin{array}{c}\text { NLC1 } \\
2 \\
\end{array}$ & & 8.5 & & 1.5 & & 3 & & 87 & 50 \\
\hline SLN1 & 10 & & & & & 3 & & 87 & 50 \\
\hline SLN2 & 10 & & & & & & 3 & 87 & 50 \\
\hline
\end{tabular}

ATO

\section{Particle size and polydispersity index}

The mean diameter and polydispersity index of particle of nanostructured lipid carriers loaded with EGCG was determined using a Zetasizer Nano-ZS (Malvern Instruments, Worceshtire (UK), equipped with a $10 \mathrm{~mW}$ He-Ne laser employing the wavelength of $633 \mathrm{~nm}$ and a back-scattering angle of $90^{\circ}$ at $25{ }^{\circ} \mathrm{C}$. Before Photon correlation spectroscopic (PCS) analysis, EGCG-NLCs formulations should be diluted with a certain amount of double-distilled water (1:200) to get appropriate scattering intensity. The analysis, of Particle size was determined using Mie theory with the refractive index and absorbance of lecithin at 1.490 and 0.100 , respectively (Gu et al., 2019; Li et al., 2016; Shah et al., 2014; Wolf et al., 2018).

\section{Zeta potential analysis}

The zeta potential of NLC formulations was measured via electrophoretic mobility measurements using a Zetasizer Nano-ZS (Malvern Instruments, Worceshtire (UK). The zeta potential was calculated by applying the Helmholtz-Smoluchowski equation ( $n=3$ ) (Marques et al., 2017). 


\section{Entrapment efficiency (EE)}

The entrapment efficiency of EGCG into NLC formulations were determined by the indirect method by measuring the concentration of the free EGCG. Initialy, $2 \mathrm{ml}$ of NLCs formulations were centrifuged at $100,000 \mathrm{rpm}$ for $1 \mathrm{~h}$ at $4{ }^{\circ} \mathrm{C}$ to evaluate the unentraped EGCG using cooling ultracentrifuge (Beckman Instruments TLX-120 Optima Ultracentrifuge) (Nafee et al., 2018; Safwat et al., 2017; Tatke et al., 2019; Tiwari and Pathak, 2011). The aqueous layer was aspirated and filtered using Millipore ${ }^{\circledR}$ membrane $(0.22 \mu \mathrm{m})$ and diluted with appropriate amount of double distilled water and measured by UV-Vis spectrophotometer (Shimadzu, the model UV1800 PC, Kyoto, Japan) at $273 \mathrm{~nm}$ to determine the unencapsulated EGCG. Consequently, entrapment efficiency of EGCG into NLCs were determined by the following equations

$\mathrm{EE} \%=\{($ weight of initial drug - weight of free drug) / (weight of free drug) X 100 $\}$

\section{In-vitro drug release study}

The in vitro release of EGCG from EGCG solution and EGCG-NLCs was performed by a dialysis bag diffusion technique. The receptor compartments consist of phosphate buffer solution (PBS) of pH 6.8 (Shtay et al., 2019). The donor compartment is cellulose membrane dialysis bags (MWCO-12 000, Sigma, USA) were soaked in dissolution media overnight prior experiment. $1 \mathrm{ml}$ of freshly prepared EGCG-NLCs and EGCG solution (equivalent to $0.5 \mathrm{mg}$ of EGCG) were diluted with $5 \mathrm{ml}$ of dissolution media and which tightly closed from two sides by thermo-resistant thread. The bags were immersed in Dissolution apparatus, (six-spindle dissolution tester, Pharmatest, type PTWII, Germany) automatically adjusted at $37 \pm 2{ }^{\circ} \mathrm{C}$ and $100 \mathrm{rpm} .2$ $\mathrm{ml}$ sample was aspirated at a predetermined time interval $(1,2,4,6,8,10,12$ and $24 \mathrm{~h}$ ) and the same amount of media was replaced to maintain sink condition. The release of free EGCG from NLC was compared to that from solution. The aspirated samples were measured using UV-Vis spectrophotometer at $273 \mathrm{~nm}$.

\section{Particle morphology}

Morphology of the EGCG loaded NLC was determined by transmission electron microscopy (JOEL Transmission electron microscope (JTEM) model 1010 Tokyo, Japan) to investigate the outer layer of nanoparticles. The sample for TEM observation was prepared by placing few drops of EGCG loaded NLC dispersion that was previously diluted 50-fold with double-distilled water onto a 400-mesh carbon film coated copper grid followed by negative staining with $1 \%$ phosphotungstic acid for 10 s. The sample was dried in air before TEM observation (Anwar et al., 2020).

\section{RESULTS and DISCUSSION:}

\section{Physicochemical characterization of EGCG-NLCs and EGCG-SLNs formulations}

Particle size, polydispersity index (PDI) and zeta potential ( $\zeta)$ measurement 
Particle size, PDI and zeta potential are the physical properties of the colloidal dispersion determining stability of the formulation. Particle sizing is a significant method for confirming nanosized particle manufacturing. Also, Particle size played a crucial role in the gastrointestinal uptake and their clearance by the reticuloendothelial system. Hence, the precise determination of the particle size was very important. Usually, particle size less than $300 \mathrm{~nm}$ was advisable for the intestinal transport (Harde et al., 2011; Wang et al., 2013).

As represented in table (2) and figure (1) the observations revealed that all the designed formulations were in the colloidal nanometer range $(\leq 380 \mathrm{~nm})$. It can be concluded that particle size of Precirol ® ATO5 nanoparticles (NLC1 to NLC4), GMS nanoparticles (NLC5 to NLC8), and Compritol® 888 ATO nanoparticles (NLC9 to NLC12) ranged from $(241.37 \pm 10.61$ to $295.43 \pm 7.18 \mathrm{~nm}),(253.34 \pm 8.67$ to $308.45 \pm 8.94$ $\mathrm{nm})$ and $(261.21 \pm 9.17$ to $301.89 \pm 7.94 \mathrm{~nm})$ respectively. The obtained results were clearly distinguished that formulations which contain pluronic F68 give the small particle size than that contain tween 60 as in F3, F7 and F11 (205.34 \pm 10.58 , $220.35 \pm 7.71$ and $214.44 \pm 8.01 \mathrm{~nm}$ ) this findings may be attributed to HLB values of surfactants where HLB value of pluronic F68 (HLB 29) higher than that of tween 60 (HLB 15.6) (Anwar et al., 2019; Malkani et al., 2014).

On the other hand, the largest particle size was exhibited in formula SLN1 and SLN2 (379.34 \pm 9.47 and $364.11 \pm 9.68)$ respectively, which contain solid lipid only Precirol ${ }^{\circledR}$ ATO5 as lipid phase to form solid lipid nanoparticles. this observation can be explained by the absence of liquid lipid in lipid phase (Bahari and Hamishehkar, 2016; Nafee et al., 2018).

Table (2): Particle size, and polydispersity indices of EGCG-NLCs and EGCG-SLNs formulations

\begin{tabular}{|c|c|c|c|c|}
\hline $\begin{array}{c}\text { Formulae } \\
\text { Number }\end{array}$ & Particle size (nm) & RO & PDI & RO \\
\hline NLC1 & $241.37 \pm 10.61$ & 4 & $0.15 \pm 0.09$ & 2 \\
\hline NLC2 & $273.67 \pm 9.47$ & 7 & $0.12 \pm 0.06$ & 1 \\
\hline NLC3 & $205.34 \pm 10.58$ & 1 & $0.18 \pm 0.09$ & 5 \\
\hline NLC4 & $295.43 \pm 7.18$ & 10 & $0.25 \pm 0.04$ & 11 \\
\hline NLC5 & $253.34 \pm 8.67$ & 5 & $0.20 \pm 0.05$ & 8 \\
\hline NLC6 & $288.22 \pm 7.84$ & 8 & $0.35 \pm 0.04$ & 14 \\
\hline NLC7 & $220.35 \pm 7.71$ & 3 & $0.17 \pm 0.04$ & 4 \\
\hline NLC8 & $308.45 \pm 8.94$ & 12 & $0.28 \pm 0.05$ & 12 \\
\hline NLC9 & $261.21 \pm 9.17$ & 6 & $0.15 \pm 0.06$ & 2 \\
\hline NLC10 & $292.24 \pm 8.47$ & 9 & $0.21 \pm 0.04$ & 9 \\
\hline NLC11 & $214.44 \pm 8.01$ & 2 & $0.24 \pm 0.02$ & 10 \\
\hline NLC12 & $301.89 \pm 7.94$ & 11 & $0.28 \pm 0.04$ & 12 \\
\hline SLN1 & $379.34 \pm 9.47$ & 14 & $0.19 \pm 0.04$ & 7 \\
\hline SLN2 & $364.11 \pm 9.68$ & 13 & $0.18 \pm 0.03$ & 5 \\
\hline
\end{tabular}




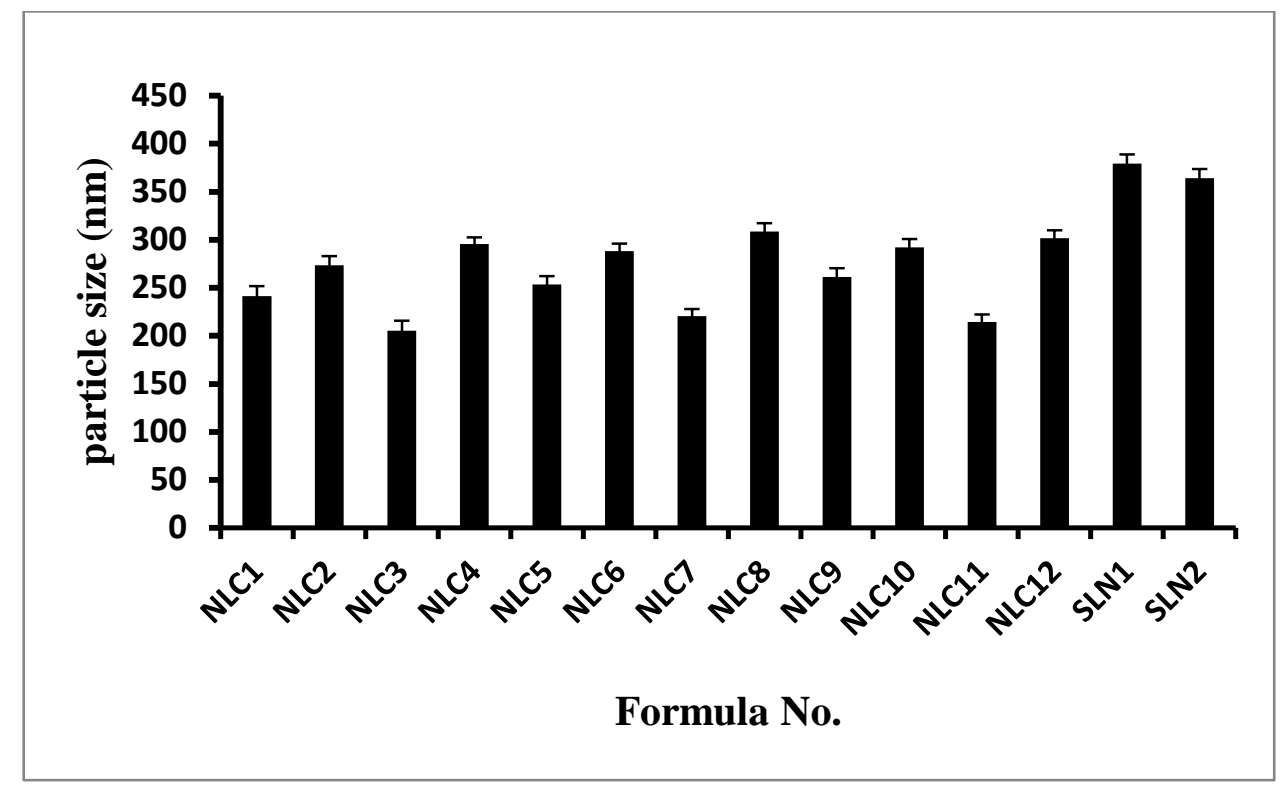

Figure 1: Mean particle size of EGCG-NLCs and EGCG-SLNs formulations

the polydispersity index as an indicator of the size distribution width of the particle. The PI value that reflects dispersion quality typically varies between 0 and 1 . Most researchers recognize PI values $\leq 0.3$ as optimum values; however, values $\leq 0.5$ are also acceptable (Anwar et al., 2020; Kaur et al., 2008).

Table (2) Also, give an overview of the results of polydispersity index measurements. The prepared NLC and SLN dispersions had a PI value ranged from $(0.12 \pm 0.06$ to $0.35 \pm 0.04)$ due to preparation method used indicating a homogenous and narrow size distribution of nanoparticles of NLCs.

The zeta potential value is a crucial parameter that influences the storage stability of nanocarriers, since it is related to the surface charge of nanoparticles and indicates the degree of repulsion between closely positioned and similarly charged particles in dispersion (López-García and Ganem-Rondero, 2015; Montenegro et al., 2016).

From the factors which mainly influence zeta potential of lipid-based nanoparticles structure of solid and liquid lipid and the medium composition (LópezGarcía and Ganem-Rondero, 2015; Noh et al., 2017) also it depends on higher steric stabilization and lower an electrostatic stabilization of nonionic surfactants which perfectly forming a coat around the particles of NLCs. Result in surface coverage of NLC decreases the electrophoretic mobility of nanoparticles and thus lower the zeta potential values(Burra et al., 2013; Dudhipala and Veerabrahma, 2016; Martins et al., 2012; Shah et al., 2014; Tatke et al., 2019).This phenomenon explains the higher stability of lipid based nanoparticles despite having a lower zeta potential value. 
Zeta potential values of all designed formulations are shown in table (3) and represented in figure (2). The results revealed that the $\mathrm{ZP}$ of the various formulations was consistently negative surface charge. ZP values of Precirol ${ }^{\circledR}$ ATO 5 nanoparticles (F1 to F4), Compritol ${ }^{\circledR} 888$ ATO nanoparticles (F5 and F8) and GMS nanoparticles (F9 to F12) in between $(-16.6 \pm 2.81$ to $-15.4 \pm 2.64 \mathrm{mV}),(-19.7 \pm 3.17$ to $-16.7 \pm 2.64 \mathrm{mV})$ and $(-30.2 \pm 2.97$ to $-27.6 \pm 2.07 \mathrm{mV})$ respectively.

Surfactants were used as stabilizer for the lipid nanoparticles prepared does not contribute with additional charges to zeta potential because of non-ionic behavior of these molecules. Thus, this molecule does not contribute with additional charges to zeta potential.

Furthermore, the solid lipids were used in developed NLCs composed of mixture of acylglycerols: Precirol ${ }^{\circledR}$ ATO 5 composed of glyceryl tripalmitostearate (25\% - 35\%), glyceryl dipalmitostearate (40\% - 60\%) and glyceryl monopalmitostearate (8\% - 22\%) (Martins et al., 2011; Raymond C Rowe, 2009) and Compritol ${ }^{\circledR} 888$ ATO composed of glyceryl tribehenate $(28 \%-32 \%)$, glyceryl dibehenate $(52 \%-54 \%)$ and glyceryl monobehenate (12\% - 18\%) (López-García and Ganem-Rondero, 2015;

Raymond C Rowe, 2009), both of them being glycerol esters of long chain-length fatty acids $(\mathrm{C} 18, \mathrm{C} 16)$ and $(\mathrm{C} 22)$ respectively. so that they provide neither charge nor polarity that contributes to zeta potential. Also, GMS composed of triacylglycerols $(5-15 \%)$, diacylglycerols $(30-45 \%)$ and monoacylglycerols $(40-55 \%)$ (Raymond C Rowe, 2009). In such case due to high content of partial emulsifying glycerides (mono and diglycerides) of GMS and presence of non-esterified hydroxyl group of the glycerol, this molecule exhibits certain polarity that contributes to zeta potential.

On the other hand, the liquid lipids were used in developed NLCs composed of diacylglycerol of medium-chain-length fatty acids. Liquid lipids provide the majority impaction and contributes to zeta potential due to its polarity which result from nonesterified hydroxyl group of the glycerol and the length of the fatty acids. These observations are in line with studies reported by (López-García and Ganem-Rondero, 2015; Teeranachaideekul et al., 2008) which stated that, it might be due to the accumulation of oil at the surface of NLC. Being the melting point of the solid lipid higher than that of the oil, when preparing NLC, the solid lipid recrystallizes first, holding a portion of the oil within the solid lipid matrix. Subsequently, the excess of oil remains in the outer shell of nanoparticles, then the oil contributes largely to zeta potential (Doktorovová et al., 2010; Jores et al., 2005).

the obtained results can be concluded that GMS nanoparticles (F9 to F12) possessed high zp values than that of Precirol ${ }^{\circledR}$ ATO 5 nanoparticles (F1 to F4) and Compritol ${ }^{\circledR} 888$ ATO nanoparticles (F5 and F8) this fact can be explained by the following reasons. certain polarity and emulsifying properties of GMS resulted from none esterified hydroxyl group of glycerol and the length of the fatty acids. Other reason was attributed to the negative charged carboxylic groups of MCT (Miglyol) which composed of diesters of caprylic/capric triglyceride. A similar explanation has been reported by Teeranachaideekul et al, 2007 (Teeranachaideekul et al., 2007), these revealed the higher ZP values of GMS nanoparticles than other nanoparticles. 
The lowest ZP values were observed in formulations of SLN1 and SLN2 ($8.3 \pm 1.54$ and $-9.2 \pm 1.64$ ) respectively, due to the absence of liquid lipid in lipid phase and presence only precirol ${ }^{\circledR}$ as solid lipid which has no role at ZP values as mentioned above (López-García and Ganem-Rondero, 2015; Raymond C Rowe, 2009).

Table (3): zeta potential of EGCG-NLCs and EGCG-SLNs formulations

\begin{tabular}{|c|c|c|}
\hline Formulae Number & Zeta potential & RO \\
\hline NLC1 & $-16.6 \pm 2.81$ & 10 \\
\hline NLC2 & $-13.3 \pm 2.64$ & 12 \\
\hline NLC3 & $-18 . \pm 1.27$ & 7 \\
\hline NLC4 & $-15.4 \pm 2.64$ & 11 \\
\hline NLC5 & $-19.7 \pm 3.17$ & 6 \\
\hline NLC6 & $-17.4 \pm 1.35$ & 8 \\
\hline NLC7 & $-20.4 \pm 2.94$ & 5 \\
\hline NLC8 & $-16.7 \pm 2.64$ & 9 \\
\hline NLC9 & $-30.2 \pm 2.97$ & 2 \\
\hline NLC10 & $-23.8 \pm 1.08$ & 4 \\
\hline NLC11 & $-32.8 \pm 1.84$ & 1 \\
\hline NLC12 & $-27.6 \pm 2.07$ & 3 \\
\hline SLN1 & $-11.3 \pm 1.54$ & 14 \\
\hline SLN2 & $-13.2 \pm 1.64$ & 13 \\
\hline
\end{tabular}

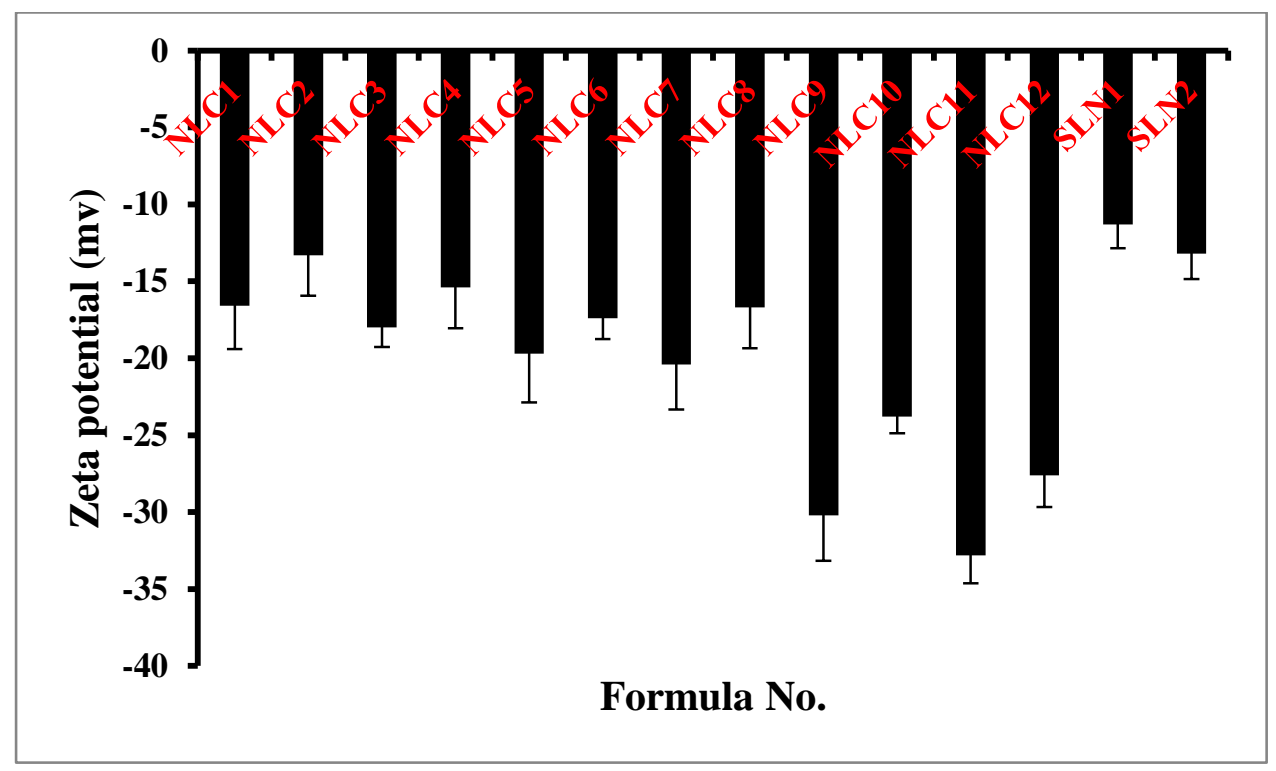

Figure 2: Zeta potential of EGCG-NLCs and EGCG-SLNs formulations

\section{Entrapment Efficiency of EGCG -NLCs and EGCG-SLNs}

The quantity of drug encapsulated in the nanoparticles and the drug content in the lipid matrix are a further significant consideration for the optimization of NLC. the quantity of drug encapsulated in the lipid matrix depends on many factors as the type of 
lipids used, physicochemical properties of the drug, miscibility and solubility of drug in the molten lipid (Indu Pal Kaur et al., 2014), physical and chemical nature of the lipid matrix and crystalline state of lipid matrix and also surfactant was found to affect encapsulation efficiency (Chantaburanan et al., 2017; Müller et al., 2000; Tatke et al., 2019). Entrapment efficiency of all lipid-based nanoparticles formulations are showed in table (4) and demonstrated in figure (3). The entrapment efficiency was determined and found to be in between $74.88 \pm 6.51 \%$ to $47.34 \pm 2.06 \%$.

The using of a combination of highly ordered with less ordered lipids, which caused several crystal defects in lipid matrix and provided much imperfections leading to void spaces in which more drug molecules could be accommodated as depicted in NLCs formulations compared with SLN formulations (Mendes et al., 2019; Tatke et al., 2019; Tran et al., 2014; Wang et al., 2013).

It was observed that E.E of EGCG in Precirol® ATO 5 nanoparticles (F1 to F4) were varied from $74.88 \pm 6.51 \%$ to $62.46 \pm 3.65 \%$, in Compritol® 888 ATO nanoparticles (F5 and F8) were varied from $72.23 \pm 1.38 \%$ to $60.97 \pm 2.32 \%$ and in GMS nanoparticles (F9 to F12) also were ranged from $67.67 \pm 2.94 \%$ to $55.23 \pm 1.82 \%$.

From the results it was clearly distinguished that Precirol® ATO 5 nanoparticles and Compritol® 888 ATO nanoparticles showed higher entrapment efficiency than that of GMS nanoparticles such fact was attributed to the chemical composition of each one where the imperfect matrix structure of Precirol ${ }^{\circledR}$ ATO 5 and Compritol ${ }^{\circledR} 888$ ATO molecules, which are formed due to the mono-, di- and triglyceride contents that expected to exhibit lower crystallinity and highly porous structural characteristics which allows higher solubility and easier accommodation of more drug molecules (Anwar et al., 2020; Khames et al., 2019; Vivek et al., 2007a).

Also, Precirol ${ }^{\circledR}$ ATO 5 is a di-glyceride with two different chain length fatty acids palmitic and stearic acid (C16 and C18); therefore, it is expected to have less ordered lipid network compared to GMS, and thus lead to the more drug molecules could be entrapped (Khames et al., 2019; Vivek et al., 2007b).

Regarding the type of surfactant, it was clearly observed that lipid-based nanoparticles formulation prepared using Pluronic ${ }^{\circledR}$ F68 higher E.E. than that prepared using another surfactant as demonstrated in F3, F7, F11 and SLN2. This fact might be attributed to high value of hydrophilic - lipophilic balance of pluronic $®$ F68 (HLB 29) compared to another surfactant. 
Table (4): Entrapment efficiency of EGCG-NLCs and EGCG-SLNs formulations

\begin{tabular}{|c|c|c|}
\hline Formulae Number & $\begin{array}{c}\text { Entrapment Efficiency } \pm \text { SD } \\
(\% \mathrm{w} / \mathrm{w})\end{array}$ & $\mathrm{RO}$ \\
\hline NLC1 & $74.88 \pm 6.51$ & 2 \\
\hline NLC2 & $70.39 \pm 2.14$ & 5 \\
\hline NLC3 & $76.12 \pm 1.62$ & 1 \\
\hline NLC4 & $62.46 \pm 3.65$ & 9 \\
\hline NLC5 & $72.23 \pm 1.38$ & 4 \\
\hline NLC6 & $69.87 \pm 4.62$ & 6 \\
\hline NLC7 & $74.76 \pm 2.74$ & 3 \\
\hline NLC8 & $60.97 \pm 2.32$ & 10 \\
\hline NLC9 & $67.67 \pm 2.94$ & 8 \\
\hline NLC10 & $60.55 \pm 1.05$ & 11 \\
\hline NLC11 & $68.56 \pm 2.45$ & 7 \\
\hline NLC12 & $55.23 \pm 1.82$ & 12 \\
\hline SLN1 & $47.34 \pm 2.06$ & 14 \\
\hline SLN2 & $49.45 \pm 3.06$ & 13 \\
\hline
\end{tabular}

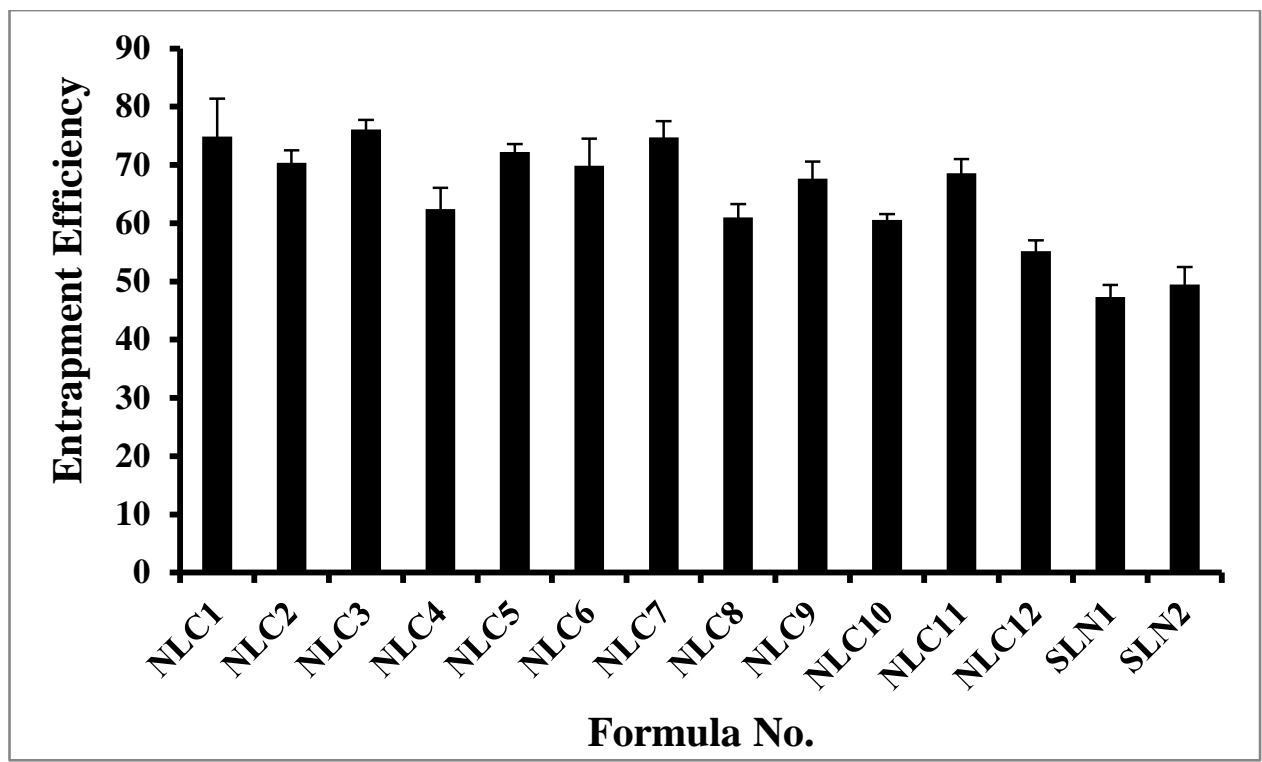

Figure 3: Entrapment efficiency of EGCG-NLCs and EGCG-SLNs formulations

\section{In-vitro release study}

In-vitro release study was achieved for all formulations in addition to pure EGCG solution. The release condition monitored in PBS (pH 7.4) to achieve "sink" conditions during a dissolution test for all formulation. It was observed that EGCG solution showed almost complete drug release (100\%) within $4 \mathrm{~h}$.

On the other side, the EGCG-NLCs and EGCG-SLNs formulations exhibited prolonged release over the incubation time ranged from $(67.1 \pm 8.1$ to $51.2 \pm 6.5 \%$ and 
$72.2 \pm 9.1$ to $66.9 \pm 6.8 \%$ ) respectively, at the end of the incubation in dissolution media as depicted in figures (4-7). This was expected and indicates the release of encapsulated EGCG from the NLCs and SLNs, Due to the large surface area and its nanosized (Shtay et al., 2019; Zhang and Zhang, 2018). In addition, there was no significant difference in the release profiles of all developed formulations.

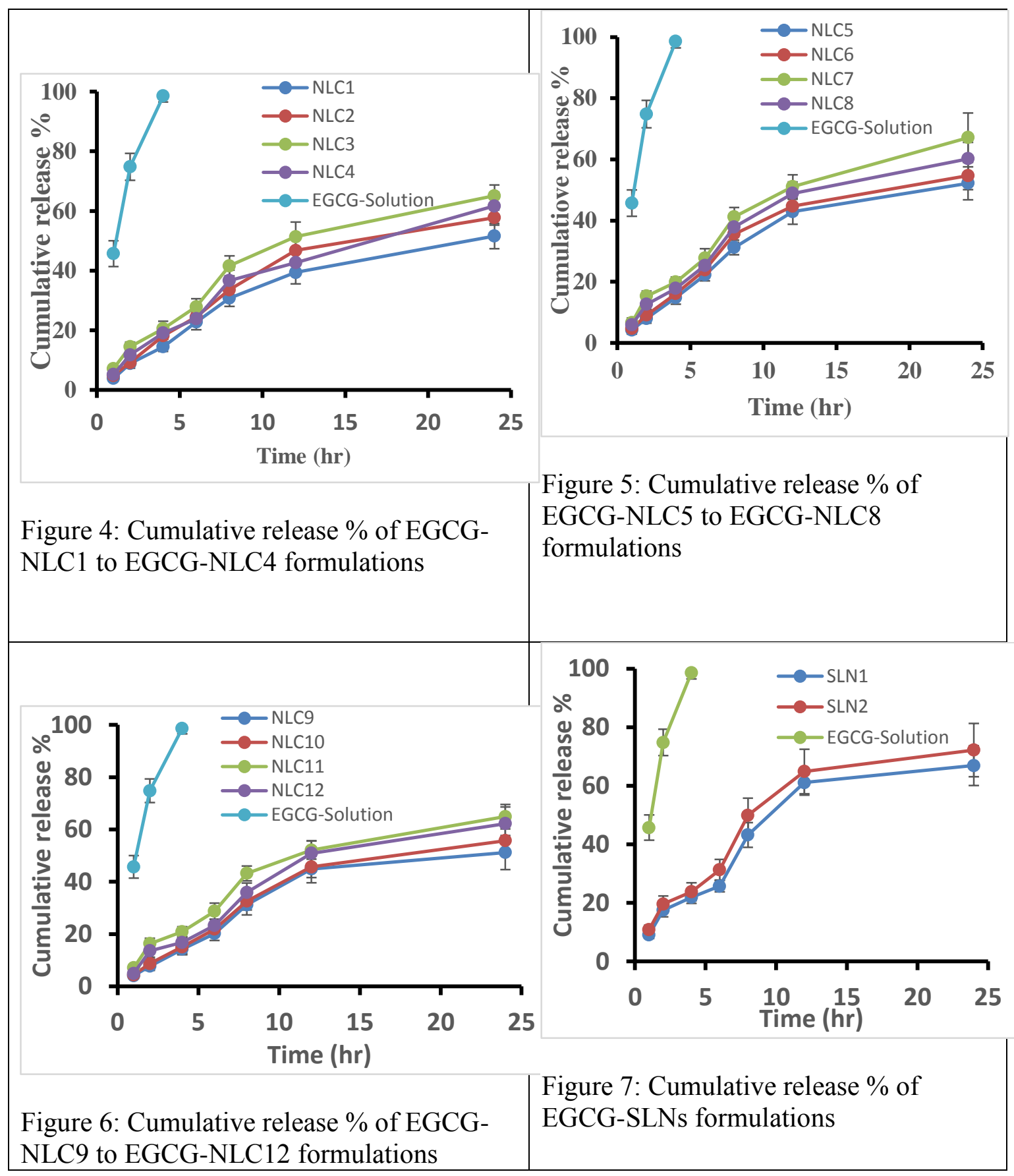


Table (5): Cumulative release \% of EGCG formulations

\begin{tabular}{|c|c|c|c|c|c|c|c|c|}
\hline Formula & $1 \mathrm{hr}$ & $2 \mathrm{hr}$ & $4 \mathrm{hr}$ & $6 \mathrm{hr}$ & $8 \mathrm{hr}$ & $12 \mathrm{hr}$ & $24 \mathrm{hr}$ & $\mathrm{RO}$ \\
\hline NLC1 & 3.9 & 8.9 & 14.5 & 22.8 & $30 . .8$ & 39.4 & 51.6 & 2 \\
\hline NLC2 & 4.9 & 9.2 & 18.2 & 24.5 & 33.6 & 46.8 & 57.8 & 6 \\
\hline NLC3 & 7.2 & 14.5 & 20.6 & 27.9 & 41.6 & 51.4 & 65.1 & 11 \\
\hline NLC4 & 5.2 & 11.8 & 19.1 & 23.9 & 36.7 & 42.7 & 61.7 & 8 \\
\hline NLC5 & 4.2 & 8 & 14.8 & 22.2 & 31.2 & 42.9 & 52.2 & 3 \\
\hline NLC6 & 4.7 & 9.1 & 16.1 & 23.9 & 35.6 & 44.7 & 54.7 & 4 \\
\hline NLC7 & 6.6 & 15.3 & 19.9 & 27.7 & 41.2 & 51.1 & 67.1 & 13 \\
\hline NLC8 & 5.9 & 12.6 & 17.8 & 25.3 & 37.9 & 48.9 & 60.2 & 7 \\
\hline NLC9 & 4.1 & 7.7 & 14.2 & 20.2 & 31.2 & 44.9 & 51.2 & 1 \\
\hline NLC10 & 4.4 & 8.7 & 15.1 & 21.9 & 32.6 & 45.7 & 55.7 & 5 \\
\hline NLC11 & 7.1 & 16 & 20.9 & 28.7 & 43.2 & 52.1 & 64.9 & 10 \\
\hline NLC12 & 4.9 & 13.6 & 16.8 & 23.3 & 35.9 & 50.9 & 62.2 & 9 \\
\hline SLN1 & 9.1 & 17.5 & 21.9 & 25.7 & 43.2 & 61.1 & 66.9 & 12 \\
\hline SLN2 & 10.9 & 19.6 & 23.8 & 31.3 & 49.9 & 64.9 & 72.2 & 14 \\
\hline
\end{tabular}

Table (6): Total rank order of GCG-NLCs and EGCG-SLNs formulations

\begin{tabular}{|c|c|c|c|c|c|c|c|c|c|}
\hline $\begin{array}{c}\text { Formulae } \\
\text { Number }\end{array}$ & PS & PDI & ZP & EE\% & Total & RO & $\begin{array}{c}\text { In- } \\
\text { vitro } \\
\text { release }\end{array}$ & Total & RO \\
\hline NLC1 & 4 & 2 & 10 & 2 & 18 & 3 & 2 & 5 & 2 \\
\hline NLC2 & 7 & $\mathbf{1}$ & 12 & 5 & 25 & 7 & 6 & 13 & 5 \\
\hline NLC3 & $\mathbf{1}$ & 5 & 7 & 1 & 14 & 1 & 11 & 12 & 4 \\
\hline NLC4 & 10 & 11 & 11 & 9 & 41 & 11 & 8 & 19 & 7 \\
\hline NLC5 & 5 & 8 & 6 & 4 & 23 & 6 & 3 & 9 & 3 \\
\hline NLC6 & 8 & 14 & 8 & 6 & 36 & 9 & 4 & 13 & 5 \\
\hline NLC7 & 3 & 4 & 5 & 3 & 15 & 2 & 13 & 15 & 6 \\
\hline NLC8 & 12 & 12 & 9 & 10 & 43 & 12 & 7 & 19 & 7 \\
\hline NLC9 & 6 & 2 & 2 & 8 & 18 & 3 & 1 & 4 & 1 \\
\hline NLC10 & 9 & 9 & 4 & 11 & 32 & 8 & 5 & 13 & 5 \\
\hline NLC11 & 2 & 10 & $\mathbf{1}$ & 7 & 20 & 5 & 10 & 15 & 6 \\
\hline NLC12 & 11 & 12 & 3 & 12 & 38 & 10 & 9 & 19 & 7 \\
\hline SLN1 & 14 & 7 & 14 & 14 & 49 & 14 & 12 & 26 & 8 \\
\hline SLN2 & 13 & 5 & 13 & 13 & 44 & 13 & 14 & 27 & 9 \\
\hline
\end{tabular}




\section{Morphology of EGCG-NLC9}

The morphology and presence of colloidal nanoparticles of EGCG-NLC3 was determined by transmission electron microscope and was showed in figure (8). TEM images illustrated that EGCG-NLC9 were of uniform distribution, separate and almost spherical shapes. This result might be based on particles developed using chemically polydispersed lipids are almost spherical as in present study (Dingler et al., 1999). The TEM micrograph showed that EGCG-NLC9 were nanometer-sized particles around 200 $\mathrm{nm}$ which in proximity with the observations yielded by a Malvern ${ }^{\circledR}$ Zetasizer Nano ZS90 (Malvern ${ }^{\circledR}$ Instruments Limited, Worcestershire, UK) and there were no crystals of free drug observed.

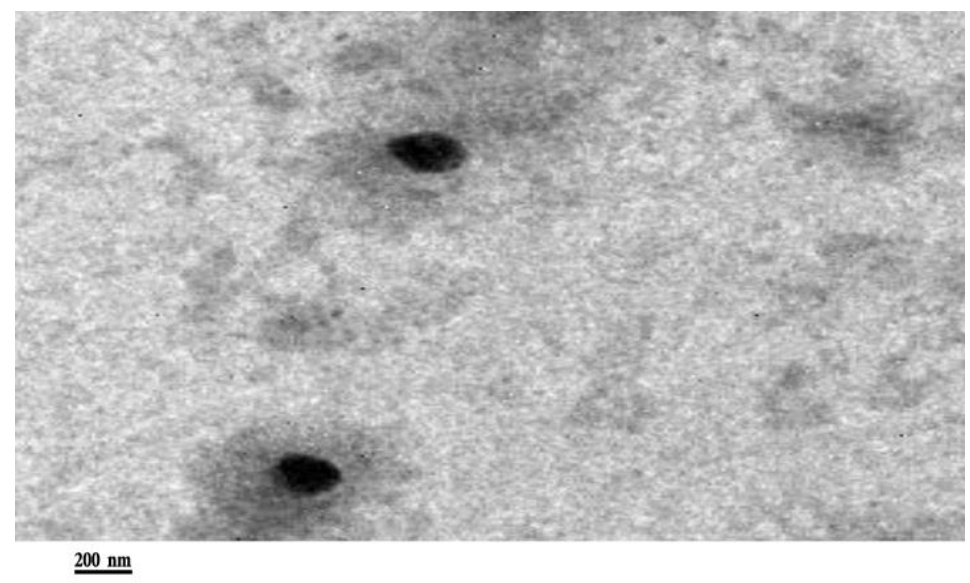

Figure 8: Transmission electron microscope image of EGCG-NLC9

\section{Conclusion}

Lipid based nanoparticles (NLCs and SLNs) are adaptable nanoparticles with multipurpose applications. However, quality and successful incorporation of EGCG into NLC and SLN to develop more efficient formulations were perquisite for the oral bioavailability improving. In current study, EGCG-NLCs and EGCG-SLNs were successfully formulated by hot homogenization - ultrasonication technique. Furthermore, the developed formulations were subjected to physicochemical characterization. The developed EGCG-NLCs and EGCG-SLNs showed small and homogeneous particle size approximately (205 and $379 \mathrm{~nm}$ ) with entrapment efficiency around (47.34 and 76.12\%) respectively. Also, the resulted formulation EGCG-NLC9 appeared under transmission electron microscope in almost spherical shape.

\section{REFERENCES}

Anwar, W., Dawaba, H.M., Afouna, M.I., Samy, A.M., (2019) . SCREENING STUDY FOR FORMULATION VARIABLES IN PREPARATION AND CHARACTERIZATION OF CANDESARTAN CILEXETIL LOADED NANOSTRUCTURED LIPID CARRIERS. Univers. J. Pharm. Res. 4, 8-19. doi:10.22270/ujpr.v4i6.330 
Anwar, W., Dawaba, H.M., Afouna, M.I., Samy, A.M., Rashed, M.H., Abdelaziz, A.E., (2020). Enhancing the oral bioavailability of candesartan cilexetil loaded nanostructured lipid carriers: In vitro characterization and absorption in rats after oral administration. Pharmaceutics 12, 1-19. doi:10.3390/pharmaceutics 12111047

Attama, A.A., Momoh, M.A., Builders, P.F., (2012) . Lipid Nanoparticulate Drug Delivery Systems: A Revolution in Dosage Form Design and Development, in: Recent Advances in Novel Drug Carrier Systems. pp. 107-140. doi: $10.5772 / 50486$

Bahari, L.A.S., Hamishehkar, H., (2016). The impact of variables on particle size of solid lipid nanoparticles and nanostructured lipid carriers; A comparative literature review. Adv. Pharm. Bull. 6, 143-151. doi:10.15171/apb.2016.021

Burra, M., Jukanti, R., Janga, K.Y., Sunkavalli, S., Velpula, A., Ampati, S., Jayaveera, K.N., (2013). Enhanced intestinal absorption and bioavailability of raloxifene hydrochloride via lyophilized solid lipid nanoparticles. Adv. Powder Technol. 24, 393-402. doi:10.1016/j.apt.2012.09.002

Chantaburanan, T., Teeranachaideekul, V., Chantasart, D., Jintapattanakit, A., Junyaprasert, V.B.,(2017). Effect of binary solid lipid matrix of wax and triglyceride on lipid crystallinity, drug-lipid interaction and drug release of ibuprofen-loaded solid lipid nanoparticles (SLN) for dermal delivery. J. Colloid Interface Sci. 504, 247-256. doi:10.1016/j.jcis.2017.05.038

Cortesi, R., Valacchi, G., Muresan, X.M., Drechsler, M., Contado, C., Esposito, E., Grandini, A., Guerrini, A., Forlani, G., Sacchetti, G., (2017). Nanostructured lipid carriers (NLC) for the delivery of natural molecules with antimicrobial activity: production, characterisation and in vitro studies. J. Microencapsul. 34, 63-72. doi:10.1080/02652048.2017.1284276

Dingler, A., Blum, R.P., Niehus, H., Müller, R.H., Gohla, S., (1999). Solid lipid nanoparticles (SLN(TM)/Lipopearls(TM)) - A pharmaceutical and cosmetic carrier for the application of vitamin E in dermal products. J. Microencapsul. 16, 751-767. doi:10.1080/026520499288690

Doktorovová, S., Araújo, J., Garcia, M.L., Rakovský, E., Souto, E.B., (2010). Formulating fluticasone propionate in novel PEG-containing nanostructured lipid carriers (PEG-NLC). Colloids Surfaces B Biointerfaces 75, 538-542. doi:10.1016/j.colsurfb.2009.09.033

Dudhipala, N., Veerabrahma, K., (2016). Candesartan cilexetil loaded solid lipid nanoparticles for oral delivery: Characterization, pharmacokinetic and pharmacodynamic evaluation. Drug Deliv. 23, 395-404. doi:10.3109/10717544.2014.914986

Granja, A., Pinheiro, M., Reis, S., (2016). Epigallocatechin gallate nanodelivery 
systems for cancer therapy. Nutrients 8, 307. doi:10.3390/nu8050307

Grumezescu, A., 2016. Novel Approaches of Nanotechnology in Food, Novel Approaches of Nanotechnology in Food. Academic Press. doi:10.1016/c20150-01014-0

Gu, Y., Tang, X., Yang, M., Yang, D., Liu, J., (2019). Transdermal drug delivery of triptolide-loaded nanostructured lipid carriers: Preparation, pharmacokinetic, and evaluation for rheumatoid arthritis, International Journal of Pharmaceutics. Elsevier B.V. doi:10.1016/j.ijpharm.2018.11.024

Harde, H., Das, M., Jain, S., (2011). Solid lipid nanoparticles: an oral bioavailability enhancer vehicle. Expert Opin. Drug Deliv. 8, 1407-1424. doi: $10.1517 / 17425247.2011 .604311$

Indu Pal Kaur, Bhandari, R., Yakhmi, and J.V.,(2014). Lipids as Biological Materials for Nanoparticulate Delivery, Handbook of Nanomaterials Properties. doi:10.1007/978-3-642-31107-9

Jores, K., Haberland, A., Wartewig, S., Mäder, K., Mehnert, W., (2005). Solid Lipid Nanoparticles (SLN) and oil-loaded SLN studied by spectrofluorometry and raman spectroscopy. Pharm. Res. 22, 1887-1897. doi:10.1007/s11095-005$7148-5$

Kanwar, J., Taskeen, M., Mohammad, I., Huo, C., Chan, T.H., Dou, Q.P., (2012). Recent advances on tea polyphenols. Front. Biosci. - Elit. 4 E, 111-131. doi: $10.2741 / 363$

Kaur, I.P., Bhandari, R., Bhandari, S., Kakkar, V., (2008). Potential of solid lipid nanoparticles in brain targeting. J. Control. Release 127, 97-109. doi:10.1016/j.jconrel.2007.12.018

Khames, A., Khaleel, M.A., El-Badawy, M.F., El-Nezhawy, A.O.H., (2019). Natamycin solid lipid nanoparticles - sustained ocular delivery system of higher corneal penetration against deep fungal keratitis: Preparation and optimization. Int. J. Nanomedicine 14, 2515-2531. doi:10.2147/IJN.S190502

Klinski, E., (2013). Block Copolymer Based Composition of Epigallocatechin-3-gallate with Improved Oral Bioavailability as a Way to Increase its Therapeutic Activity. J. Nanomedine. Biotherapeutic Discov. 03. doi:10.4172/2155983x.1000117

Li, H., Chen, M., Su, Z., Sun, M., Ping, Q., (2016). Size-exclusive effect of nanostructured lipid carriers on oral drug delivery. Int. J. Pharm. 511, 524-537. doi:10.1016/j.ijpharm.2016.07.049

López-García, R., Ganem-Rondero, A., (2015). Solid Lipid Nanoparticles (SLN) and Nanostructured Lipid Carriers (NLC): Occlusive Effect and Penetration 
Enhancement Ability. J. Cosmet. Dermatological Sci. Appl. 05, 62-72. doi:10.4236/jcdsa.2015.52008

Malkani, A., Date, A.A., Hegde, D., (2014). Celecoxib nanosuspension: Single-step fabrication using a modified nanoprecipitation method and in vivo evaluation. Drug Deliv. Transl. Res. 4, 365-376. doi:10.1007/s13346-014-0201-3

Marques, A.C., Rocha, A.I., Leal, P., Estanqueiro, M., Lobo, J.M.S., (2017). Development and characterization of mucoadhesive buccal gels containing lipid nanoparticles of ibuprofen. Int. J. Pharm. 533, 455-462. doi:10.1016/j.ijpharm.2017.04.025

Martins, S., Tho, I., Ferreira, D.C., Souto, E.B., Brandl, M., (2011). Physicochemical properties of lipid nanoparticles: Effect of lipid and surfactant composition. Drug Dev. Ind. Pharm. 37, 815-824. doi:10.3109/03639045.2010.545414

Martins, S., Tho, I., Souto, E., Ferreira, D., Brandl, M., (2012). Multivariate design for the evaluation of lipid and surfactant composition effect for optimisation of lipid nanoparticles. Eur. J. Pharm. Sci. 45, 613-623. doi:10.1016/j.ejps.2011.12.015

Mathur, P., Sharma, S., Rawal, S., Patel, B., Patel, M.M., (2019). Fabrication, optimization, and in vitro evaluation of docetaxel-loaded nanostructured lipid carriers for improved anticancer activity. J. Liposome Res. 0, 1-15. doi:10.1080/08982104.2019.1614055

Mendes, I.T., Ruela, A.L.M., Carvalho, F.C., Freitas, J.T.J., Bonfilio, R., Pereira, G.R., (2019). Development and characterization of nanostructured lipid carrier-based gels for the transdermal delivery of donepezil. Colloids Surfaces B Biointerfaces 177, 274-281. doi:10.1016/j.colsurfb.2019.02.007

Montenegro, L., Lai, F., Offerta, A., Sarpietro, M.G., Micicchè, L., Maccioni, A.M., Valenti, D., Fadda, A.M., (2016). From nanoemulsions to nanostructured lipid carriers: A relevant development in dermal delivery of drugs and cosmetics. J. Drug Deliv. Sci. Technol. 32, 100-112. doi:10.1016/j.jddst.2015.10.003

Müller, R.H., Mäder, K., Gohla, S., (2000). Solid lipid nanoparticles (SLN) for controlled drug delivery - A review of the state of the art. Eur. J. Pharm. Biopharm. 50, 161-177. doi:10.1016/S0939-6411(00)00087-4

Nafee, N., Makled, S., Boraie, N., (2018). Nanostructured lipid carriers versus solid lipid nanoparticles for the potential treatment of pulmonary hypertension via nebulization. Eur. J. Pharm. Sci. 125, 151-162. doi:10.1016/j.ejps.2018.10.003

Noh, G.Y., Suh, J.Y., Park, S.N., (2017). Ceramide-based nanostructured lipid carriers for transdermal delivery of isoliquiritigenin: Development, physicochemical characterization, and in vitro skin permeation studies. Korean J. Chem. Eng. 
34, 400-406. doi:10.1007/s11814-016-0267-3

Poonia, N., Kharb, R., Lather, V., Pandita, D., (2016). Nanostructured lipid carriers: versatile oral delivery vehicle. Futur. Sci. OA 2, FSO135. doi:10.4155/fsoa2016-0030

Rawal, S., Patel, M.M., (2019). Threatening cancer with nanoparticle aided combination oncotherapy. J. Control. Release 301, 76-109. doi:10.1016/j.jconrel.2019.03.015

Raymond C Rowe, P.J.S. and M.E.Q., (2009). Handbook of Pharmaceutical Excipients, sixth Edition, the Pharmaceutical Press, london. doi:10.1016/s0168-3659(01)00243-7

Safwat, S., Ishak, R.A.H., Hathout, R.M., Mortada, N.D., (2017). Nanostructured lipid carriers loaded with simvastatin: effect of PEG/glycerides on characterization, stability, cellular uptake efficiency and in vitro cytotoxicity. Drug Dev. Ind. Pharm. 43, 1112-1125. doi:10.1080/03639045.2017.1293681

Shah, R., Eldridge, D., Palombo, E., Harding, I., (2014). Optimisation and stability assessment of solid lipid nanoparticles using particle size and zeta potential. J. Phys. Sci. 25, 59-75.

Shtay, R., Keppler, J.K., Schrader, K., Schwarz, K., (2019). Encapsulation of (-)epigallocatechin-3-gallate (EGCG) in solid lipid nanoparticles for food applications. J. Food Eng. 244, 91-100. doi:10.1016/j.jfoodeng.2018.09.008

Tatke, A., Dudhipala, N., Janga, K.Y., Balguri, S.P., Avula, B., Jablonski, M.M., Majumdar, S., (2019). In situ gel of triamcinolone acetonide-loaded solid lipid nanoparticles for improved topical ocular delivery: Tear kinetics and ocular disposition studies. Nanomaterials 9, 1-17. doi:10.3390/nano9010033

Teeranachaideekul, V., Boonme, P., Souto, E.B., Müller, R.H., Junyaprasert, V.B., (2008). Influence of oil content on physicochemical properties and skin distribution of Nile red-loaded NLC. J. Control. Release 128, 134-141. doi:10.1016/j.jconrel.2008.02.011

Teeranachaideekul, V., Souto, E.B., Junyaprasert, V.B., Müller, R.H., (2007). Cetyl palmitate-based NLC for topical delivery of Coenzyme Q10 - Development, physicochemical characterization and in vitro release studies. Eur. J. Pharm. Biopharm. 67, 141-148. doi:10.1016/j.ejpb.2007.01.015

Tiwari, R., Pathak, K., (2011). Nanostructured lipid carrier versus solid lipid nanoparticles of simvastatin: Comparative analysis of characteristics, pharmacokinetics and tissue uptake. Int. J. Pharm. 415, 232-243. doi:10.1016/j.ijpharm.2011.05.044

Tran, T.H., Ramasamy, T., Truong, D.H., Choi, H.G., Yong, C.S., Kim, J.O., (2014). 
Preparation and Characterization of Fenofibrate-Loaded Nanostructured Lipid Carriers for Oral Bioavailability Enhancement. AAPS PharmSciTech 15, 15091515. doi:10.1208/s12249-014-0175-y

Vivek, K., Reddy, H., Murthy, R.S.R., (2007)a. Investigations of the effect of the lipid matrix on drug entrapment, in vitro release, and physical stability of olanzapine-loaded solid lipid nanoparticles. AAPS PharmSciTech 8, 16-24. doi:10.1208/pt0804083

Vivek, K., Reddy, H., Murthy, R.S.R., (2007)b. Investigations of the effect of the lipid matrix on drug entrapment, in vitro release, and physical stability of olanzapine-loaded solid lipid nanoparticles. AAPS PharmSciTech 8, 16-24. doi: $10.1208 / \mathrm{pt} 0804083$

Wang, Q., Cheng, H., Zhou, K., Wang, L., Dong, S., Wang, D., Chen, W., (2013). Nanostructured lipid carriers as a delivery system of biochanin A. Drug Deliv. 20, 331-337. doi:10.3109/10717544.2013.838716

Wolf, M., Reiter, F., Heuser, T., Kotisch, H., Klang, V., Valenta, C., (2018). Monoacyl-phospatidylcholine based drug delivery systems for lipophilic drugs: Nanostructured lipid carriers vs. nano-sized emulsions. J. Drug Deliv. Sci. Technol. 46, 490-497. doi:10.1016/j.jddst.2018.06.010

Zhang, G., Zhang, J., (2018). Enhanced oral bioavailability of EGCG using pHsensitive polymeric nanoparticles: Characterization and in vivo investigation on nephrotic syndrome rats. Drug Des. Devel. Ther. 12, 2509-2518. doi:10.2147/DDDT.S172919

Zou, L. qiang, Peng, S. feng, Liu, W., Gan, L., Liu, W. lin, Liang, R. hong, Liu, C. mei, Niu, J., Cao, Y. lin, Liu, Z., Chen, X., (2014). Improved in vitro digestion stability of (-)-epigallocatechin gallate through nanoliposome encapsulation. Food Res. Int. 64, 492-499. doi:10.1016/j.foodres.2014.07.042 
صياغة وتوصيف ابيجالوكاتيكين جالات المحمل علي جزيئات دهنية متتاهية الصغر لتحسين

\section{اتاحتها الحيوية وخصائصها الفيزيقية}

صبرى عبد القادر الطويله '،،عبدالعزيز السيد عبدالعزيز' ، محمود عبد الغنى مهدى' ، هناء عبد الفتاح الغمرى' ' قسم الصيدلانيات و الصيدلة الصناعية ـ كلية الصيدلة - جامعة الزقازيق

× ق قسم التكنولوجيا الصيدلانية ـ كلية الصيدلة - جامعة كفر الثيخ

seltawela71@gmail.com : البريد الاكتروني للباحث الرئيسي:*

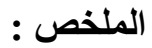

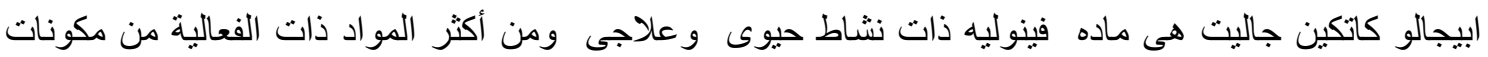

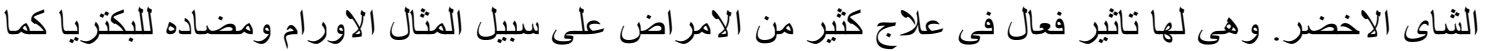

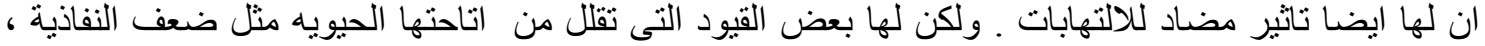
و التقارب الثنديد لآلية تدفق البروتين السكري المعوي ونصف العمر القصير . لذلك ، في هذه الدراسة الحالية.

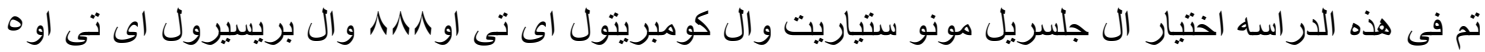

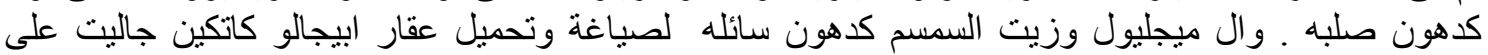
جزيئات دهنيه متناهية الصغر و التى تم تحضير ها معمليا بتقنية التجانس الساخن و الموجات فوق الصوتيه.

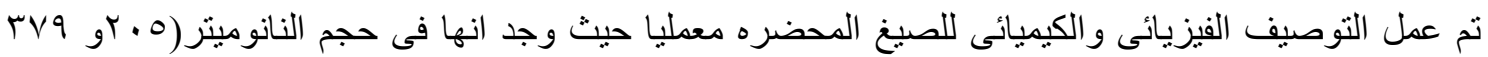

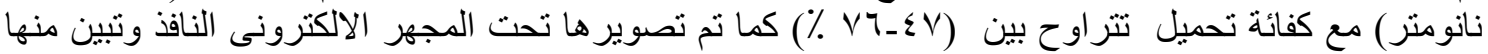
كروية الثكل للجزيئات الدهنيه متناهية الصغر المحضره معمليا

الكلمات المفتاحية : ابيجالوكاتيكين جالات, حجم الجزيئات, سعة التحميل, المجر الالكتروني النافذ' الاطلاق الحيوي المعملي المفتي 